\title{
Facial diplegia: etiology, clinical manifestations, and diagnostic evaluation
}

\author{
Diplegia facial: etiologia, manifestações clínicas, e avaliação diagnóstica \\ Sefer Varol, Hasan Huseyin Ozdemir, Esref Akil, Demet Arslan, M. Ufuk Aluclu, Caner F. Demir, Yavuz Yucel
}

\begin{abstract}
Objective: Facial diplegia (FD) is a rare neurological manifestation with diverse causes. This article aims to systematically evaluate the etiology, diagnostic evaluation and treatment of FD. Method: The study was performed retrospectively and included 17 patients with a diagnosis of FD. Results: Patients were diagnosed with Guillain-Barré syndrome (GBS) (11), Bickerstaff's brainstem encephalitis (1), neurosarcoidosis (1), non-Hodgkin's Lymphoma (1), tuberculous meningitis (1) herpes simplex reactivation (1) and idiopathic (1). In addition, two patients had developed FD during pregnancy. Conclusion: Facial diplegia is an ominous symptom with widely varying causes that requires careful investigation.
\end{abstract}

Keywords: facial diplegia, Guillain-Barré syndrome, pregnancy, treatment.

\section{RESUMO}

Objetivo:Diplegia facial (DF)éuma manifestação neurológica rara proveniente de diferentes causas. Este artigo visa avaliar sistematicamente a etiologia, avaliação diagnóstica e tratamento de DF. Método: 0 estudo foi retrospectivo e incluiu 17 pacientes com diagnóstico de FD. Resultados: Os pacientes foram diagnosticados como casos de síndrome de Guillain-Barré (SGB) (11), encefalite de tronco de Bickerstaff (1), neurosarcoidose (1), linfoma não-Hodgkin's (1), meningite tuberculosa (1) reativação de herpes simplex (1) e causa idiopática (1). Além disto, duas pacientes haviam desenvolvido DF durante a gestação. Conclusão: Diplegia facial é uma manifestação com diversas causas que requer investigação cuidadosa.

Palavras-chave: diplegia facial, síndrome de Guillain-Barré, gravidez, tratamento.

Most of the muscles of the face are controlled by the facial nerve, which originates from the cerebellopontine angle - the lateral part of pontomedullary junction. The pathways of the facial nerve are variable, and knowledge of the key intratemporal and extratemporal landmarks is essential for accurate physical diagnosis. The spectrum of facial nerve dysfunction has a wide degree of variability in motor and sensory functioning.

Unilateral facial nerve palsy, with an incidence of around 25 per 100,000 population, is a common neurologic disorder mimicking stroke ${ }^{1}$. Facial diplegia (FD) represents less than $2 \%$ of all facial palsy cases and has an incidence of 1 per $5,000,000$ population ${ }^{2,3}$. The differential diagnosis of its causes is extensive and hence can present as a diagnostic challenge. Physicians should be aware of these various diagnostic possibilities, some of which are potentially fatal. Facial diplegia may be the first symptom that requires early treatment in many diseases.

Facial diplegia is an extremely rare. In the literature, only one study evaluated the etiology and management of
$\mathrm{FD}^{2}$. Early diagnosis of some diseases, increase in laboratory studies, and treatment options may be the cause of some variability in etiologic factors.

\section{METHOD}

The study was performed retrospectively. In this study, 17 patients with a diagnosis of FD were followed and treated between January 2008 and January 2014 in Neurology of Firat and Dicle University Hospitals. Excluded from the study were diagnosed congenital FD and pediatric patients. An experienced neurologist evaluated the neurological deficits on admission. Information on the patients' histories, antecedent infectious symptoms, neurological findings, chest X-ray (or MRI), brain MRI, cerebrospinal fluid (CSF) and electrophysiological examination results were collected. Facial muscle function evaluated using House Brackmann grading system ${ }^{4}$. Facial nerve electromyography were performed 14 to 21 days after

Dicle University, Department of Neurology, Diyarbakir, Turkey.

Correspondence: Hasan Huseyin Ozdemir; Dicle University, Department of Neurology; Diyarbakir 21280, Turkey; E-mail: drhasanh@gmail.com

Conflict of interest: There is no conflict of interest to declare.

Received 19 January 2015; Received in final form 06 June 2015; Accepted 26 June 2015. 
the onset of palsy. Also, peripheral nerve conduction studies were performed within 4 weeks of onset of neurological symptoms and were repeated if the initial conduction studies were normal. Patients were classified as having acute inflammatory demyelinating polyradiculoneuropathy (AIDP) or acute motor sensory axonal neuropathy (AMSAN) on the basis of the electrodiagnostic criteria proposed by Ho et al. ${ }^{5}$.

The complete blood count, liver function tests, plasma urea, creatinine, electrolyte, and plasma glucose levels, antinuclear antibody, thyroid function, antiacetylcholine receptor antibodies, thyroid peroxidase antibodies, antinuclear antibody and CSF biochemical parameters were evaluated.

Virological and microbiological studies evaluated a variety of infections (Borrelia burgdorferi, syphillis HSV-1/2, VZV, EBV, CMV, HHV-6) in the serum and CSF. Serum IgG and IgM antibodies to gangliosides GM1, GM2, GM1b, GD1a, GD1b, GalNAc-GD1a, GT1a, and GQ1b were investigated by enzyme-linked immunosorbent assay (ELISA).

Patients received treatment during hospitalization and outpatient records after discharge were examined. Improvements in levels of FD were evaluated over a period of 1-3 months.

\section{RESULTS}

Seventeen patients with FD were detected/analysed for the underlying causes. Twelve of the patients were female and five of them were male. Eleven patients (64.7\%) were diagnosed with GBS fulfilling the clinical and electrophysiological criteria ${ }^{6}$. Different subtypes of GBS based on electrophysiological abnormalities included AIDP in 10, AMSAN in 1 patients. One of them presented with FD at the onset of illness and other patients developed FD 2-7 days after onset GBS. IVIG was administered to these patients and only one patient died. Complete recovery was seen in four patients and partial recovery was observed in six. Data on the patients are provided in Table.

Other etiological factors in our patients was detected; brainstem encephalitis (1), neurosarcoidosis (1), non-Hodgkin's Lymphoma (1), tuberculous meningitis (1), herpes simplex reactivation (1), and idiopathic (1). The patients who had tuberculous meningitis and non-Hodgkin's Lymphoma died.

Two patients had developed FD during pregnancy. One of these patients was diagnosed with tuberculous meningitis and did not respond to treatment and later died. The other pregnant patient was considered to have idiopathic FD and partially recovered with steroid therapy.

\section{DISCUSSION}

The most important part of the evaluation of a patient with FD is a thorough history and physical examination focusing on the head and neck region and the neurological system. The work-up should include complete blood count, fasting glucose, erythrocyte sedimentation rate, fluorescent treponemal antibody test, HIV test, Lyme titer, and antinuclear antibody level measurement. Contrast-enhanced MRI scan, if done in the appropriate clinical setting, may detect a positive radiographic diagnosis. The areas that are most important to visualize are the central nervous system, skull base, meninges, and cerebellopontine angle. Lumbar puncture after an MRI scan as well as special facial nerve function tests can also be performed.

One of the most common underlying causes of FD is GBS. During the course of illness, 24-60\% of GBS patients develop facial nerve paresis, and almost all show it bilaterally ${ }^{7}$. Also, Miller Fisher syndrome is considered a variant of GBS, and FD may be seen $^{8}$. In a 23-year review, Keane et al. found that out of 43 patients with FD as the predominant sign, GBS were one of the common underlying causes. Among the cases, two out of the five with GBS progressed clinically; information on the others was not available ${ }^{2}$. Eleven patients $(64.7 \%)$ were diagnosed with GBS in our study, one of them presented with FD at the onset of illness. Ten patients developed FD, 2-7 days after onset GBS. In our study, the most common cause of FD was GBS. Anti-ganglioside antibody tests were administered our patients but they were not detected. Purely isolated FD associated with distinctly positive anti-GM2, anti-GD1a, and anti-GD1b antibodies is exceedingly rare 9 . On the other hand, we more frequently observed AIDP in patients with FD. However, we cannot speculate on the possible cause of this, because AIDP is the most common form of GBS .

Causes of FD other than GBS are very diverse. Active HSV-1 infections as well as post-infectious immune-mediated mechanism have been associated with facial paralysis. HSV-1 DNA has been found by PCR analysis in biological samples of patients with unilateral facial paralysis. Also, HSV-1 related FD is rarely monitored $^{10}$. HSV-1 DNA was detected in the CSF of one patient, and we think that it could indicate a possible viral association with FD.

Effects of lymphoma on the peripheral nervous system have been reviewed ${ }^{11}$. In the literature, Re et al. described a case of GBS in a patient with non-Hodgkin's lymphoma, and FD was seen in that patient. It is unusual to see neurological symptoms such as FD in patients with malignant lymphoma. Acute lymphoblastic leukemia may present with $\mathrm{FD}^{12}$. On the other hand, lymphomatous meningitis is a profoundly morbid and often fatal CNS metastasis that develops in at least $4 \%-8 \%$ of patients with non-Hodgkin lymphoma ${ }^{13}$. Facial diplegia can be developed lymphomatous meningitis. Our patient used vincristine for lymphoma treatment. Vincristine-induced neurotoxicity has been reported, especially as cranial and peripheral neuropathy ${ }^{14}$. Also, we detected multiple cranial neuropathies. Facial diplegia may be associated with vincristine-induced neurotoxicity or lymphomatous meningitis.

Facial diplegia is very rarely seen during pregnancy. A few cases have been reported. Many factors may lead to FD during pregnancy. Idiopathic cases have been reported ${ }^{15}$. We identified two pregnant patients with FD. Tuberculous meningitis was determined one patient and the other was considered idiopathic. According to Mari et al., FD seems to be 


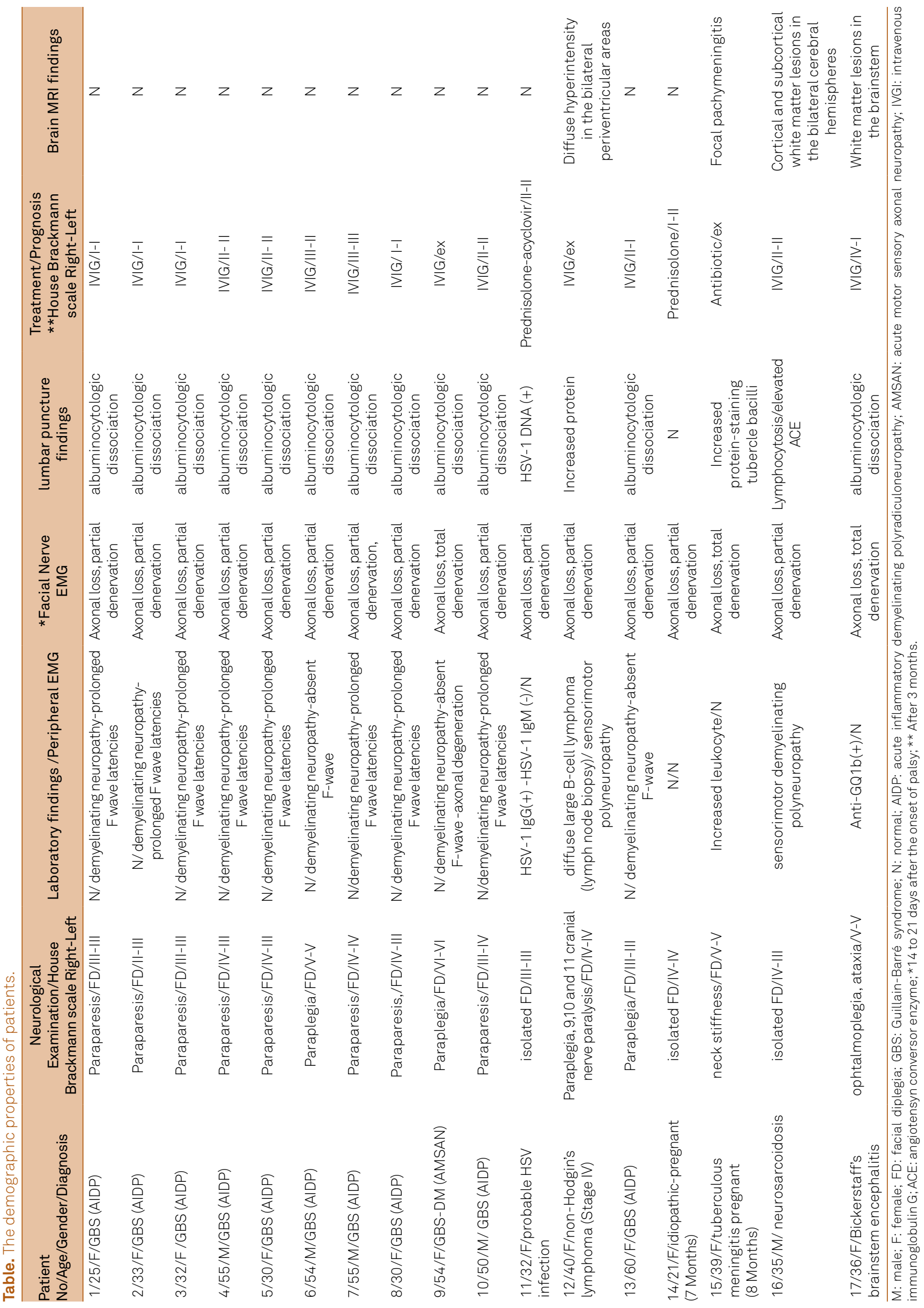


more frequent during the last trimester of pregnancy and in the early postpartum period ${ }^{15}$. Facial diplegia was seen our patients in the last trimester. The tuberculous meningitis patient did not respond to any treatment and subsequently died. The patient with idiopathic FD had a partial recovery.

Also, the etiology of FD includes many conditions such as congenital, Bickerstaff's brainstem encephalitis, tuberculous meningitis, sarcoidosis traumatic, Lyme disease, diabetes mellitus, metabolic, toxic (thallium), and immunoallergic ${ }^{2,16,17,18,19,20,21,22,23}$. In our study, we did not detect Hansen's disease, syphilis, Lyme disease, intracranial tumors or cryptococcal meningitis, unlike the studies from Keane et al. ${ }^{2}$. We detected HSV-1, neurosarcoidosis and non-Hodgkin's lymphoma. This condition may arise from early diagnosis, new developments of laboratory tests and treatments.

Treatment for patients with facial paralysis varies according to the etiology. Clinical evaluation for both the severity of paralysis and the presence of complications is the first step before the start of treatment or rehabilitation. In FD with GBS, the standard treatments for GBS are reasonable'. Short-term steroid therapy is beneficial for patients with idiopathic FD. In herpes zoster infections, acyclovir may be a useful treatment approach in Bell's palsy ${ }^{24}$. Corticosteroid therapy is recommended in most cases of neurosarcoidosis with FD as spontaneous recovery cannot be predicted ${ }^{25}$. Treatment protocol of FD is not clear in the pregnancy and it depends on underlying cause. Corticosteroids did not appear to influence the outcome of Bell's palsy in pregnancy ${ }^{26}$. On the other hand, corticosteroid therapy is controversial in pregnant patients with FD. However, in our patient, a partial recovery was seen with corticosteroid treatment.

Limitations of this study are short follow-up period, the abscense of different outcome scores obtained by interviews and the small size of the study group. Another limitation is that we could not evaluate the effect of FD on the prognosis of GBS as the present study is a retrospective study.

In conclusion, FD may be due to a life-threatening condition. Therefore, the practitioner should be aware of the diagnostic possibilities that cause this extremely rare condition and treat.

\section{References}

1. Pothiawala S, Lateef F. Bilateral facial nerve palsy: a diagnostic dilemma. Case Rep Emerg Med. 2012;2012:458371. doi:10.1155/2012/458371

2. Keane JR. Bilateral seventh nerve palsy: analysis of 43 cases and review of the literature. Neurology. 1994;44(7):1198-202. doi:10.1212/WNL.44.7.1198

3. Teller DC, Murphy TP. Bilateral facial paralysis: a case presentation and literature review. J Otolaryngol. 1992;21(1):44-7.

4. House JW, Brackmann DE. Facial nerve grading system. Otolaryngol Head Neck Surg. 1985;93(2):146-7.

5. Griffin JW, Li CY, Ho TW, Xue P, Macko C, Gao CY et al. Guillain-Barré syndrome in northern China. The spectrum of neuropathological changes in clinically defined cases. Brain. 1995;118(Pt 3):577-95. doi:10.1093/brain/118.3.577

6. Asbury AK, Cornblath DR. Assessment of current diagnostic criteria for GB syndrome. Ann Neurol. 1990;27(S1 suppl):521-4. doi:10.1002/ana.410270707

7. Lehmann HC, Macht S, Jander S, Hartung HP, Methner A. Guillain-Barré syndrome variant with prominent facial diplegia, limb paresthesia, and brisk reflexes. J Neurol. 2012;259(2):370-1. doi:10.1007/s00415-011-6169-8

8. Curtis CE, Barnes EV, Dupiche CA. Guillain-Barré syndrome variant: presenting with myalgias and acute facial diplegia. Mil Med. 2008;173(5):507-8. doi:10.7205/MILMED.173.5.507

9. Susuki K, Koga M, Hirata K, Isogai E, Yuki N. A Guillain-Barré syndrome variant with prominent facial diplegia.J Neurol. 2009:256(11):1899-905. doi:10.1007/s00415-009-5254-8

10. Pretegiani E, Rosini F, Donati D, Rufa A, Moschettini D, Cerase A et al Idiopathic bilateral facial palsy: is a causative role of anti-GM1 ganglioside and herpes simplex type 1 possible? Neurol Sci. 2012;33(4):951-3. doi:10.1007/s10072-011-0832-9

11. Vallat JM, De Mascarel HA, Bordessoule D, Jauberteau MO, Tabaraud F, Gelot A et al. Non-Hodgkin malignant lymphomas and peripheral neuropathies: 13 cases. Brain. 1995;118(5):1233-45. doi:10.1093/brain/118.5.1233

12. Schattner A, Kozack N, Sandler A, Shtalrid M. Facial diplegia as the presenting manifestation of acute lymphoblastic leukemia. Mt Sinai J Med. 2001;68(6):406-9.

13. Van Horn A. Lymphomatous meningitis: early diagnosis and treatment. Clin J Oncol Nurs. 2009;13(1):90-4. doi:10.1188/09.CJON.90-94
14. Yalin SF, Trabulus S, Yalin AS, Yalin GY, Ongoren S, Altiparmak MR. Vocal cord paralysis during the treatment of mantle cell lymphoma with vincristine. Int J Clin Pharm. 2013;35(3):306-8. doi:10.1007/s11096-013-9751-6

15. Mari I, Pouchot J, Grasland A, Vinceneux P. Facial diplegias during pregnancy. Presse Med. 2000;29(40):2213-5. Frenche.

16. Odaka M, Yuki N, Yamada M, Koga M, Takemi T, Hirata K et al. Bickerstaff's brainstem encephalitis: clinical features of 62 cases and a subgroup associated with Guillain-Barré syndrome. Brain. 2003;126(10):2279-2290. doi:10.1093/brain/awg233

17. Thwaites GE, Tran TH. Tuberculous meningitis: many questions, too few answers. Lancet Neurol. 2005;4(3):160-70. doi:10.1016/S1474-4422(05)70019-3

18. Said G, Lacroix C, Planté-Bordeneuve V, Le Page L, Pico F, Presles $O$ et al. Nerve granulomas and vasculitis in sarcoid peripheral neuropathy: a clinicopathological study of 11 patients. Brain. 2002;125(2):264-75. doi:10.1093/brain/awf027

19. Adour K, Wingerd J, Doty HE. Prevalence of concurrent diabetes mellitus and idiopathic facial paralysis (Bell's palsy). Diabetes. 1975;24(5):449-51. doi:10.2337/diab.24.5.449

20. Raucq E, Dupuis MJ (1998) Facial diplegia after hymenoptera sting. Acta Neurol Belg. 1998;98(2):215-20.

21. Tromme I, Van Neste D, Dobbelaere F, Bouffioux B, Courtin C, Dugernier Tet al. Skin signs in the diagnosis of thallium poisoning. Br J Dermatol. 1998;138(2):321-5. doi:10.1046/j.1365-2133.1998.02083.x

22. Undabeitia J, Liu B, Pendleton C, Nogues P, Noboa R, Undabeitia JI. Bilateral traumatic facial paralysis. Case report. Neurocirugia (Astur). 2013;24(5):225-8. doi:10.1016/j.neucir.2013.01.003

23. Jain V, Deshmukh A, Gollomp S. Bilateral facial paralysis: case presentation and discussion of differential diagnosis. J Gen Intern Med. 2006;21(7):C7-C10. doi:10.1111/j.1525-1497.2006.00466.x

24. Morrow MJ. Bell's Palsy and Herpes Zoster Oticus. Curr Treat Options Neurol 2000;2(5):407-16. doi:10.1007/s11940-000-0039-5

25. Hoitsma E, Faber CG, Drent M, Sharma OP. Neurosarcoidosis: a clinical dilemma. Lancet Neurol. 2004;3(7):397-407. doi:10.1016/S1474-4422(04)00805-1

26. Falco NA, Eriksson E. Idiopathic facial palsy in pregnancy and the puerperium. Surg Gynecol Obstet. 1989;169(4):337-40. 